\title{
Helicobacter pylori: A Possible Risk Factor for Bone Health
}

\author{
Yun Hee Chung, ${ }^{1,+}$, Jong Seop Gwak ${ }^{1,+}$, Sung Woo Hong', Jung Hyeon Hyeon', Cheol Min Lee², Seung Won Oh², \\ Hyuktae Kwon ${ }^{2, *}$ \\ 'Department of Family Medicine, Seoul National University, Seoul, Korea \\ ${ }^{2}$ Department of Family Medicine, Healthcare System Gangnam Center, Seoul National University Hospital, Seoul, Korea
}

Background: Helicobacter pylori (H. pylori) infection may cause systemic inflammation and increase the production of tumor necrosis factor- $\alpha$, interleukin-1, and interleukin-6. Unfortunately, bone mineral density also may be affected by these cytokines. This study aimed to evaluate the association between bone mineral density and $H$. $p y$ lori infection.

Methods: A cross-sectional study evaluated 1,126 men undergoing a comprehensive health screening in a private Korean screening center. Subjects' sera were tested for $H$. pylori antibodies (immunoglobulin G) using an enzymelinked immunosorbent assay, and bone mineral densities $\left(\mathrm{g} / \mathrm{cm}^{2}\right)$ of the lumbar spine, femoral neck, and total femur were obtained using dual-energy X-ray absorptiometry. To evaluate the difference in bone mineral density according to $H$. pylori infection status, the adjusted mean bone mineral densities at each site were compared after adjusting for potential confounders, including age, sex, body mass index, smoking, alcohol consumption, and exercise. Results: $H$. pylori infection was associated with a significant decrease in mean lumbar bone mineral density $(H$. $p y$ lori-positive, $1.190 \mathrm{~g} / \mathrm{cm}^{2} ;$ H. pylori-negative, $\left.1.219 \mathrm{~g} / \mathrm{cm}^{2} ; \mathrm{P}=0.006\right)$, which was greatest among men who were $\geq 50$ years old (H. pylori-positive, $1.193 \mathrm{~g} / \mathrm{cm}^{2} ;$ H. pylori-negative, $1.233 \mathrm{~g} / \mathrm{cm}^{2} ; \mathrm{P}=0.006$ ). However, no significant association was observed in the bone mineral densities of the total femur and femoral neck.

Conclusion: In men, H. pylori infection was negatively associated with lumbar bone mineral density. This association may be useful in the early detection, prevention, and management of male osteoporosis.

Keywords: Helicobacter pylori; Osteoporosis; Bone Density

Received: April 23, 2015, Revised: June 15, 2015, Accepted: August 21, 2015

*Corresponding Author: Hyuktae Kwon Tel: +82-2-2112-5745, Fax: +82-2-2112-5635, E-mail: hyuktae@gmail.com

tThese authors contributed equally to this work. 


\section{INTRODUCTION}

Osteoporosis is a systemic skeletal disease characterized by a relatively low bone mineral density (BMD) and increased susceptibility to fracture. ${ }^{1)}$ There is an increasing incidence of osteoporosis-related fractures and the related mortality rate, as a high proportion of the global population is affected by osteoporosis. ${ }^{2-4)}$ Although this disease historically has been considered more common among women, it has been reported recently that the prevalence of osteoporosis and fractures among men has increased, owing to their increasing life expectancy and the growing population of elderly men. ${ }^{5)}$ Almost $20 \%$ of men who are $\geq 50$ years old have osteoporosis, ${ }^{6}$ ) and femoral fracture-related deaths are more common among men than among women. ${ }^{7)}$ During their lifetime, $25 \%$ of men are likely to experience an osteoporosis-related fracture, ${ }^{8)}$ and therefore premature death and disability due to osteoporosis are recognized as important public health concerns. ${ }^{5)}$

There are two main types of osteoporosis: primary and secondary. The cause of primary osteoporosis is unknown (idiopathic osteoporosis), while that of secondary osteoporosis is relatively well understood. Approximately $40 \%$ of osteoporosis cases in men are classified as primary osteoporosis. ${ }^{7,9)}$ Therefore, the majority of male osteoporosis cases have at least one (occasionally more than one) secondary cause, and it is important to identify the risk factors associated with secondary osteoporosis, thereby facilitating the interventions needed for prevention. Known risk factors associated with osteoporosis include race, a family history of osteoporosis, age of menarche, smoking, alcohol consumption, low dietary calcium intake, lack of physical activity, various medications, various endocrine disorders, and low body weight. ${ }^{1,10)}$ Moreover, inflammatory bowel disease, celiac disease, and gastrectomy also are known risk factors of osteoporosis. ${ }^{11)}$

Helicobacter pylori (H. pylori) infection causes chronic gastritis by inducing a localized and systematic inflammatory response that may increase the concentrations of tumor necrosis factor- $\alpha$, interleukin-1, and interleukin-6, which are known to affect BMD. ${ }^{12-14)}$ However, few studies have assessed the relationship between $H$. pylori infection and BMD, especially in men. ${ }^{15-19)}$ In this study, we confined our analysis to men because the effect of estrogen on BMD is very strong compared to H. pylori. Therefore, the aim of the present study was to verify whether $H$. pylori infection is a risk factor for osteoporosis, by analyzing the relationship between $H$. pylori infection and BMD in Korean men.

\section{METHODS}

\section{Subjects}

The initial patient population for this study included 2,979 men

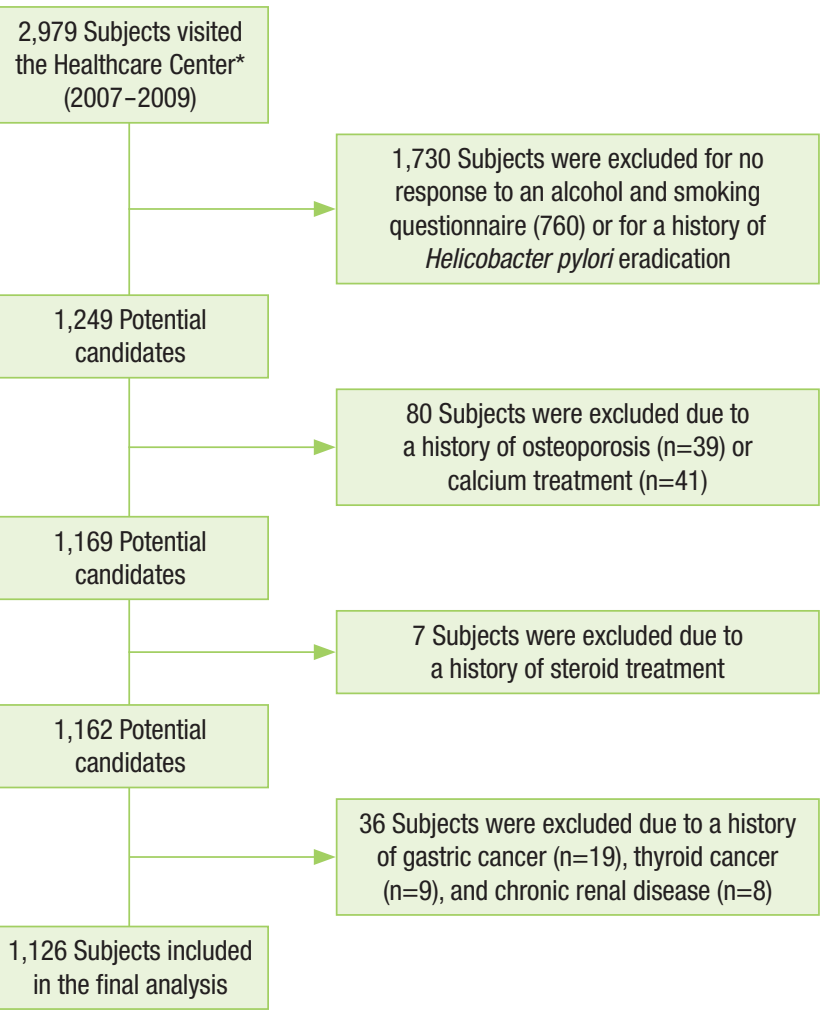

Figure 1. Selection of study subjects. *Healthcare System Gangnam Center, Seoul National University Hospital.

who visited the Seoul National University Hospital Healthcare System Gangnam Center for a comprehensive health check-up between January 2007 and December 2009. All subjects underwent a BMD test and a serum test to screen for $H$. pylori infection. We excluded 760 subjects who did not respond to a questionnaire regarding smoking, alcohol, and exercise habits. Additional exclusions included subjects who had received medications for the eradication of $H$. pylori $(\mathrm{n}=970)$, had a history of osteoporosis or treatment for osteoporosis (including calcium) $(n=80)$, or had a history of thyroid disease, chronic kidney disease, gastric cancer, or glucocorticoid medications that might have affected their BMD $(n=43)$. Thus, 1,126 men were included in our analysis (Figure 1). The study was approved by the institutional review board of Seoul National University Hospital, and the requirement for informed consent was waived owing to the retrospective nature of the analysis.

\section{Measurements}

\section{1) Helicobacter pylori infection status}

$H$. pylori infection was evaluated by measuring the serum level of $H$. pylori-specific antibodies. Titers of $H$. pylori-specific immunoglobulin $\mathrm{G}$ were measured using an enzyme linked immunosorbent assay kit (Radim Diagnostics, Rome, Italy). Per the manufacturer's instructions, subjects with titers $>30 \mathrm{U} / \mathrm{mL}$ were considered positive for $H$. pylori infection. 


\section{2) Bone mineral density measurement}

BMD was measured using dual-energy X-ray absorptiometry (Lunar BMD Prodigy, General Electrics, Fairfield, CT, USA) of the lumbar spine (L1-L4) and femur (total and neck).

\section{3) History and lifestyle}

Information regarding the subjects' medical history, current medications, smoking, alcohol consumption, and exercise habits were obtained via a self-administered questionnaire. For smoking status, the subjects were divided into three groups: non-smokers, past smokers, and current smokers. According to the reference criteria of the National Institute on Alcohol Abuse and Alcoholism, ${ }^{20)}$ the subjects were divided into three groups based on their alcohol consumption habits: non-drinkers, moderate drinkers ( $\leq 196 \mathrm{~g} / \mathrm{wk}$, corresponding to 14 drinks/ wk), and heavy drinkers (>196 g/wk). Subjects were grouped according to their exercise habits: those who regularly exercised at least once a week and those who did not exercise regularly.

\section{Statistical Analysis}

Univariate analyses were used to evaluate age, height, weight, body mass index (BMI), smoking, alcohol consumption, exercise, osteoporosis, and osteopenia. The subjects were classified into two groups according to their $H$. pylori infection status: $H$. pylori-positive and $H$. pylori-negative. To determine the difference in BMD according to $H$. pylori infection status, adjusted mean values for BMD at each site were calculated, after adjusting for potential confounders, including age, BMI, smoking, alcohol consumption, and exercise. All analyses were performed using STATA statistical software ver. 12.0 (Stata Co., College Station, TX, USA). All statistical tests were 2 -sided, and a P-value $<0.05$ was considered statistically significant.

\section{RESULTS}

\section{General Characteristics}

Among the 1,126 men included in our analysis, 469 were $H$. $p y$ lori-positive. The $H$. pylori-positive group was significantly older $(54.4 \pm 10.7$ vs. $51.9 \pm 12.1$ years; $\mathrm{P}<0.001)$ and included significantly more smokers $(43.7 \%$ vs. $41.1 \%$; $\mathrm{P}=0.022)$ compared to the $H$. pylori-negative group (Table 1 ).

\section{The Association between $H$. pylori Infection and Bone Mineral Density}

Table 2 shows the association between the subjects' $H$. pylori serological status and their BMD at the lumbar spine, femoral neck, and total femur (before and after adjusting for age, BMI, smoking status, alcohol consumption, and exercise). The mean lumbar spine BMD in the H. pylori-positive group was significantly lower than that in the $H$. pylori-negative group $(\mathrm{HP}[+]$, $1.190 \mathrm{~g} / \mathrm{cm}^{2} ; \mathrm{HP}[-], 1.219 \mathrm{~g} / \mathrm{cm}^{2} ; \mathrm{P}=0.006$ ) after adjusting for all relevant factors. However, the BMDs at the femoral neck and total femur were not significantly different in the two groups after adjusting for possible confounding factors.

We divided the subjects into two groups based on age, due to the known rapid decline of BMD after age $50:^{21)}<50$ years

Table 1. Patient characteristics according to $H$. pylori infection status $(N=1,126)$

\begin{tabular}{|c|c|c|c|}
\hline Characteristic & $\begin{array}{c}\text { H. pylori }(-) \\
(n=469)\end{array}$ & $\begin{array}{c}\text { H. pylori }(+) \\
(n=657)\end{array}$ & P-value* \\
\hline Age (y) & $51.9 \pm 12.1$ & $54.4 \pm 10.7$ & $<0.001$ \\
\hline Height (cm) & $169.8 \pm 5.7$ & $169.5 \pm 5.7$ & 0.385 \\
\hline Weight $(\mathrm{kg})$ & $71.3 \pm 9.6$ & $71.1 \pm 9.8$ & 0.731 \\
\hline Body mass index $\left(\mathrm{kg} / \mathrm{m}^{2}\right)$ & $24.7 \pm 2.8$ & $24.7 \pm 2.8$ & 0.928 \\
\hline $\begin{array}{l}\text { Smoking } \\
\text { Never } \\
\text { Current } \\
\text { Past }\end{array}$ & $\begin{array}{l}102(21.7) \\
193(41.2) \\
174(37.1)\end{array}$ & $\begin{array}{l}175(26.6) \\
287(43.7) \\
195(29.7)\end{array}$ & 0.022 \\
\hline $\begin{array}{l}\text { Alcohol (weekly amount) } \\
\text { None } \\
\text { Moderate }(\leq 196 \mathrm{~g}) \\
\text { Heavy }(>196 \mathrm{~g})\end{array}$ & $\begin{array}{l}109(23.2) \\
230(49.0) \\
130(27.7)\end{array}$ & $\begin{array}{l}179(27.2) \\
324(49.3) \\
154(23.4)\end{array}$ & 0.157 \\
\hline $\begin{array}{l}\text { Exercise } \\
\text { Yes } \\
\text { No }\end{array}$ & $\begin{array}{l}346(73.8) \\
123(26.2)\end{array}$ & $\begin{array}{l}507(77.2) \\
150(22.8)\end{array}$ & 0.190 \\
\hline $\begin{array}{l}\text { Lumbar spine } \\
\text { Normal } \\
\text { Osteopenia } \\
\text { Osteoporosis }\end{array}$ & $\begin{array}{c}369(78.7) \\
91(19.4) \\
9(1.9)\end{array}$ & $\begin{array}{c}484(73.7) \\
160(24.4) \\
13(2.0)\end{array}$ & 0.141 \\
\hline $\begin{array}{l}\text { Femoral neck } \\
\text { Normal } \\
\text { Osteopenia } \\
\text { Osteoporosis }\end{array}$ & $\begin{array}{c}410(87.4) \\
57(12.2) \\
2(0.4)\end{array}$ & $\begin{array}{c}543(82.6) \\
113(17.2) \\
1(0.2)\end{array}$ & 0.047 \\
\hline $\begin{array}{l}\text { Femoral total } \\
\text { Normal } \\
\text { Osteopenia } \\
\text { Osteoporosis }\end{array}$ & $\begin{array}{c}443(94.5) \\
26(5.5) \\
0\end{array}$ & $\begin{array}{c}625(95.1) \\
32(4.9) \\
0\end{array}$ & 0.614 \\
\hline
\end{tabular}

Values are presented as mean \pm standard deviation or number (\%).

H. pylori, Helicobacter pylori.

*From t-test (for continuous variables) or chi-square test (for categorical variables).

Table 2. A comparison of regional mean BMD according to H. pylori serologic status

\begin{tabular}{|c|c|c|c|c|c|c|c|c|c|}
\hline & \multicolumn{3}{|c|}{ Lumbar (L1-L4) } & \multicolumn{3}{|c|}{ Femoral neck } & \multicolumn{3}{|c|}{ Total femur } \\
\hline & H. pylori (-) & H. pylori (+) & P-value & H. pylori (-) & H. pylori (+) & P-value & H. pylori (-) & H. pylori (+) & P-value \\
\hline Unadjusted & $1.216 \pm 0.008$ & $1.193 \pm 0.007$ & 0.032 & $0.958 \pm 0.006$ & $0.951 \pm 0.005$ & 0.389 & $1.022 \pm 0.006$ & $1.010 \pm 0.005$ & 0.135 \\
\hline Model 1 & $1.217 \pm 0.008$ & $1.191 \pm 0.007$ & 0.014 & $0.955 \pm 0.006$ & $0.954 \pm 0.005$ & 0.903 & $1.020 \pm 0.006$ & $1.011 \pm 0.005$ & 0.258 \\
\hline Model 2 & $1.218 \pm 0.008$ & $1.190 \pm 0.007$ & 0.008 & $0.955 \pm 0.006$ & $0.953 \pm 0.005$ & 0.800 & $1.020 \pm 0.006$ & $1.011 \pm 0.005$ & 0.176 \\
\hline Model 3 & $1.219 \pm 0.008$ & $1.190 \pm 0.007$ & 0.006 & $0.955 \pm 0.006$ & $0.953 \pm 0.005$ & 0.812 & $1.021 \pm 0.006$ & $1.011 \pm 0.005$ & 0.176 \\
\hline
\end{tabular}

Values are presented as mean BMD \pm standard error. Model 1: adjusted for age. Model 2: adjusted for age and body mass index. Model 3: adjusted for age, body mass index, alcohol, smoking, and exercise.

$\mathrm{BMD}$, bone mineral density $\left(\mathrm{g} / \mathrm{cm}^{2}\right)$; H. pylori, Helicobacter pylori. 
Table 3. Mean lumbar BMD according to H. pylori serological status

\begin{tabular}{|c|c|c|c|c|c|c|}
\hline & \multicolumn{3}{|c|}{ Age $<50$ y $(n=443)$} & \multicolumn{3}{|c|}{ Age $\geq 50$ y $(n=683)$} \\
\hline & H. pylori (-) & H. pylori (+) & P-value & H. pylori (-) & H. pylori (+) & P-value \\
\hline Unadjusted & $1.196 \pm 0.010$ & $1.190 \pm 0.010$ & 0.634 & $1.231 \pm 0.012$ & $1.194 \pm 0.009$ & 0.015 \\
\hline Model 1 & $1.196 \pm 0.010$ & $1.189 \pm 0.010$ & 0.619 & $1.231 \pm 0.012$ & $1.194 \pm 0.009$ & 0.014 \\
\hline Model 2 & $1.197 \pm 0.010$ & $1.189 \pm 0.010$ & 0.590 & $1.232 \pm 0.011$ & $1.194 \pm 0.009$ & 0.009 \\
\hline Model 3 & $1.196 \pm 0.010$ & $1.189 \pm 0.010$ & 0.632 & $1.233 \pm 0.011$ & $1.193 \pm 0.009$ & 0.006 \\
\hline
\end{tabular}

Values are presented as mean lumbar (L1-L4) BMD \pm standard error. Model 1: adjusted for age. Model 2: adjusted for age and body mass index. Model 3: adjusted for age, body mass index, alcohol, smoking, and exercise.

$\mathrm{BMD}$, bone mineral density $\left(\mathrm{g} / \mathrm{cm}^{2}\right)$; H. pylori, Helicobacter pylori.

old and $\geq 50$ years old. Among subjects $<50$ years old, the mean BMD at the lumbar spine in the H. pylori-positive and H. pylo$r i$-negative groups were not significantly different $(\mathrm{HP}[+], 1.189$ $\mathrm{g} / \mathrm{cm}^{2} ; \mathrm{HP}[-], 1.196 \mathrm{~g} / \mathrm{cm}^{2} ; \mathrm{P}=0.632$ ) after adjusting for age, BMI, smoking status, alcohol consumption, and exercise. However, among subjects $\geq 50$ years old, the difference was statistically significant (HP[+], $\left.1.193 \mathrm{~g} / \mathrm{cm}^{2} ; \mathrm{HP}[-], 1.233 \mathrm{~g} / \mathrm{cm}^{2} ; \mathrm{P}=0.006\right)$. Furthermore, this difference was greater $\left(0.04 \mathrm{~g} / \mathrm{cm}^{2}\right)$ than that for patients $<50$ years old $\left(0.007 \mathrm{~g} / \mathrm{cm}^{2}\right)$ (Table 3 ).

\section{DISCUSSION}

In the present study, we analyzed the difference in BMD according to $H$. pylori infection status, and observed that $H$. pylori infection could negatively affect BMD. This effect was enhanced among men who were $\geq 50$ years old, compared to that among younger men. The reason for this finding may be related to the long-term exposure to inflammation caused by $H$. pylori infection. Therefore, we believe that monitoring for (and if necessary, eradicating) $H$. pylori infection may be warranted in this high-risk group.

The hypothesis that $H$. pylori infection can induce localized and systemic inflammation, thereby increasing the production of inflammatory cytokines such as tumor necrosis factor- $\alpha$, interleukin-1, and interleukin-6 (which are known to affect BMD) has been reported in previous studies. ${ }^{12-14,22,23)}$ Another study investigated the possibility that $H$. pylori infection might increase the risk of osteoporosis (due to altered bone metabolism) in a group of male subjects with osteoporosis. The authors examined serum antibodies to $H$. pylori and the cytotoxin-associated gene A (CagA) protein among 80 osteoporotic men and 160 controls, and found that infections with CagApositive $H$. pylori strains were more prevalent among men with osteoporosis. Therefore, infection with H. pylori strains expressing CagA may be a risk factor for osteoporosis in men. ${ }^{16)} \mathrm{An}-$ other study of 50 Western women ( $>49$ years old) who were $>5$ years after menopause examined the degree of atrophy of the gastric mucosa and prevalence of $H$. pylori infection using endoscopic biopsy. However, the authors concluded that the association between $H$. pylori infection and osteoporosis was not statistically significant. ${ }^{18)}$ It is also possible that $H$. pylori in- fected subjects, due to digestive symptoms, are more likely to take proton pump inhibitors, which in turn can affect BMD. ${ }^{24,25)}$

In the present study, a reduction in the mean lumbar BMD was observed among the $\mathrm{H}$. pylori-positive group. This finding supports the hypothesis that $H$. pylori infection may affect BMD. According to previous studies, the average annual reduction in lumbar spine BMD among men without existing osteoarthritis is approximately 0.001 to $0.006 \mathrm{~g} / \mathrm{cm}^{2}{ }^{26-28)}$ Given this relatively small average annual reduction, the mean difference of $0.029 \mathrm{~g} / \mathrm{cm}^{2}$ that we observed between the H. pylori-positive and negative groups may be of significant clinical relevance. Interestingly, the reduction in lumbar spine BMD was greatest among subjects who were $\geq 50$ years old, which may indicate that chronic infection is associated with a greater reduction in BMD.

However, unlike BMD at the lumbar spine, BMD at the femoral neck and total femur was not associated with $H$. pylori infection status. These differences might be due to the differences in the composition and characteristics of the lumbar spine and femur. Trabecular bone accounts for $70 \%$ to $100 \%$ of the lumbar spine, whereas cortical bone accounts for approximately $75 \%$ of the femur neck and $50 \%$ of the femoral diaphysis, with trabecular bone accounting for $100 \%$ of Ward's triangle. ${ }^{29)}$ Thus, the lumbar vertebrae and femur may differ in their speed of progression and features of osteoporosis, as previous studies have reported that the risk factors for osteoporosis might be different at two sites. ${ }^{30-32)}$ Therefore, we recommend that future studies focus on the mechanism through which $H$. pylori affects BMD reduction in different parts of the body.

The present study has several limitations. First, a causal relationship cannot be established, as this study was based on crosssectional data. Second, this study did not consider dietary calcium intake and serum $25-(\mathrm{OH})$ vitamin D concentrations, which might affect BMD. Third, the study population was selected from voluntary health check-up participants, which do not represent the general Korean population. Fourth, H. pylori infection was evaluated using serologic testing, rather than histological examination. However, a positive serologic result for $H$. $p y$ lori may indicate past infection, rather than a current infection, and therefore long-standing effects must be evaluated. Unfortunately, using biopsy to detect $H$. pylori infection in our clinic 
would likely lead to the selection of patients with gastritis or ulcers, thereby creating a selection bias in our analysis. Thus, evaluating the correlation between $H$. pylori infection status and BMD using serological testing could reduce this bias, and we believe this is one of the advantages of the present study.

In conclusion, we observed that $H$. pylori infection was significantly associated with a decrease in BMD at the lumbar spine after adjusting for bone-related factors that might affect BMD. Given the statistical power generated by the large study population, these results might facilitate the development of clinical interventions for screening, assessment, and management of male osteoporosis. We recommend that further prospective studies evaluate the causal relationship between $H$. pylori infection and decreased BMD among a large patient population.

\section{CONFLICT OF INTEREST}

No potential conflict of interest relevant to this article was reported.

\section{ACKNOWLEDGMENTS}

This study was supported by a grant from the Seoul National University Hospital Research Fund (number 04-2010-0420100960).

\section{REFERENCES}

1. NIH Consensus Development Panel on Osteoporosis Prevention, Diagnosis, and Therapy. Osteoporosis prevention, diagnosis, and therapy. JAMA 2001;285:785-95.

2. Holroyd C, Cooper C, Dennison E. Epidemiology of osteoporosis. Best Pract Res Clin Endocrinol Metab 2008;22:671-85.

3. Becker S, Ogon M. Epidemiology of osteoporosis. In: Becker S, Ogon M, editors. Balloon kyphoplasty. Wien: Springer; 2008. p. 1-3.

4. Rowe SM, Song EK, Kim JS, Lee JY, Park YB, Bae BH, et al. Rising incidence of hip fracture in Gwangju city and Chonnam province, Korea. J Korean Med Sci 2005;20:655-8.

5. Cummings SR, Melton LJ. Epidemiology and outcomes of osteoporotic fractures. Lancet 2002;359:1761-7.

6. Melton LJ 3rd. The prevalence of osteoporosis: gender and racial comparison. Calcif Tissue Int 2001;69:179-81.

7. Kelepouris N, Harper KD, Gannon F, Kaplan FS, Haddad JG. Severe osteoporosis in men. Ann Intern Med 1995;123:452-60.

8. Nguyen TV, Eisman JA, Kelly PJ, Sambrook PN. Risk factors for osteoporotic fractures in elderly men. Am J Epidemiol 1996;144:255-63.

9. Peris P, Guanabens N, Monegal A, Suris X, Alvarez L, Martinez de Osaba MJ, et al. Aetiology and presenting symptoms in male osteoporosis. Br J Rheumatol 1995;34:936-41.

10. Kanis JA, McCloskey EV. Risk factors in osteoporosis. Maturitas 1998; 30:229-33.

11. Bernstein CN, Leslie WD, Leboff MS. AGA technical review on osteoporosis in gastrointestinal diseases. Gastroenterology 2003;124:795-841.

12. Censini S, Lange C, Xiang Z, Crabtree JE, Ghiara P, Borodovsky M, et al. cag, a pathogenicity island of Helicobacter pylori, encodes type I-specific and disease-associated virulence factors. Proc Natl Acad Sci U S A 1996;93:14648-53.

13. Ferrari SL, Karasik D, Liu J, Karamohamed S, Herbert AG, Cupples LA, et al. Interactions of interleukin-6 promoter polymorphisms with dietary and lifestyle factors and their association with bone mass in men and women from the Framingham Osteoporosis Study. J Bone Miner Res 2004;19:552-9.

14. Chung HW, Seo JS, Hur SE, Kim HL, Kim JY, Jung JH, et al. Association of interleukin-6 promoter variant with bone mineral density in pre-menopausal women. J Hum Genet 2003;48:243-8.

15. Akkaya N, Akkaya S, Polat Y, Turk M, Turk T, Ergur S, et al. Helicobacter pylori seropositivity in patients with postmenopausal osteoporosis. J Phys Ther Sci 2011;23:61-4.

16. Figura N, Gennari L, Merlotti D, Lenzi C, Campagna S, Franci B, et al. Prevalence of Helicobacter pylori infection in male patients with osteoporosis and controls. Dig Dis Sci 2005;50:847-52.

17. Asaoka D, Nagahara A, Hojo M, Sasaki H, Shimada Y, Yoshizawa T, et al. The relationship between H. pylori infection and osteoporosis in Japan. Gastroenterol Res Pract 2014;2014:340765.

18. Kakehasi AM, Mendes CM, Coelho LG, Castro LP, Barbosa AJ. The presence of Helicobacter pylori in postmenopausal women is not a factor to the decrease of bone mineral density. Arq Gastroenterol 2007;44:26670 .

19. Kakehasi AM, Rodrigues CB, Carvalho AV, Barbosa AJ. Chronic gastritis and bone mineral density in women. Dig Dis Sci 2009;54:819-24.

20. National Institute on Alcohol Abuse and Alcoholism. A pocket guide for alcohol screening and brief intervention [Internet]. Rockville (MD): National Institute on Alcohol Abuse and Alcoholism; 2005 [cited 2008 Aug 14]. Available from: http://pubs.niaaa.nih.gov/publications/Practitioner/PocketGuide/pocket.pdf.

21. National Osteoporosis Foundation. Clinician's guide to prevention and treatment of osteoporosis. Washington (DC): National Osteoporosis Foundation; 2010.

22. Kowalski M, Konturek PC, Pieniazek P, Karczewska E, Kluczka A, Grove $\mathrm{R}$, et al. Prevalence of Helicobacter pylori infection in coronary artery disease and effect of its eradication on coronary lumen reduction after percutaneous coronary angioplasty. Dig Liver Dis 2001;33:222-9.

23. Tasker PN, Albagha OM, Masson CB, Reid DM, Ralston SH. Association between TNFRSF1B polymorphisms and bone mineral density, bone loss and fracture. Osteoporos Int 2004;15:903-8.

24. Yang YX, Lewis JD, Epstein S, Metz DC. Long-term proton pump inhibitor therapy and risk of hip fracture. JAMA 2006;296:2947-53.

25. Freedberg DE, Haynes K, Denburg MR, Zemel BS, Leonard MB, Abrams JA, et al. Use of proton pump inhibitors is associated with fractures in young adults: a population-based study. Osteoporos Int 2015 May 19 [Epub].

26. Mazess RB, Barden HS, Drinka PJ, Bauwens SF, Orwoll ES, Bell NH. Influence of age and body weight on spine and femur bone mineral density in U.S. white men. J Bone Miner Res 1990;5:645-52.

27. Warming L, Hassager C, Christiansen C. Changes in bone mineral density with age in men and women: a longitudinal study. Osteoporos Int 2002;13:105-12.

28. Szulc P, Marchand F, Duboeuf F, Delmas PD. Cross-sectional assessment of age-related bone loss in men: the MINOS study. Bone 2000; 
26:123-9.

29. Yang SH. Basic science of bone densitometry. Proceedings of the 2008 Conference of the Korean Society of Osteoporosis; 2008 Nov 16; Seoul, Korea. Seoul: Chungwoon; 2008. p. 83-100.

30. Kim EH, Joh HK, Kim EY, Cho DY, Kweon HJ, Choi JK, et al. Biochemical markers and health behavior related with bone mineral density in adult men. Korean J Fam Med 2009;30:359-68.
31. Downey PA, Siegel MI. Bone biology and the clinical implications for osteoporosis. Phys Ther 2006;86:77-91.

32. Boonen S, Cheng XG, Nijs J, Nicholson PH, Verbeke G, Lesaffre E, et al. Factors associated with cortical and trabecular bone loss as quantified by peripheral computed tomography (pQCT) at the ultradistal radius in aging women. Calcif Tissue Int 1997;60:164-70. 